\title{
Morphological and Phylogenetic Characterization of Tyrophagus putrescentiae Schrank (Sarcoptiformes : Acaridae) from Hypsizygus marmoreus in Korea
}

\section{Choi, Kwang Shik}

Laboratory of Forest Resources Management, Division of Agro-environmental Sciences, Department of Forest Environmental Sciences, Faculty of Agriculture, Kyushu University I College of Natural Science, Kyungpook National University

\section{Park, Jae Seok}

Laboratory of Forest Resources Management, Division of Agro-environmental Sciences, Department of Forest Environmental Sciences, Faculty of Agriculture, Kyushu University I Evergreen Shimeji Farm

\section{Lee, Seung-Yeol}

Laboratory of Forest Resources Management, Division of Agro-environmental Sciences, Department of Forest Environmental Sciences, Faculty of Agriculture, Kyushu University | College of Agriculture and Life Sciences, Kyungpook National University

Hwang, Do-Un

Laboratory of Forest Resources Management, Division of Agro-environmental Sciences, Department of Forest Environmental Sciences, Faculty of Agriculture, Kyushu University / College of Natural Science, Kyungpook National University

他

https://doi.org/10.5109/1798135

出版情報: 九州大学大学院農学研究院紀要. 62 (1)，pp.9-13，2017-02-24. Faculty of Agriculture， Kyushu University

バージョン :

権利関係: 


\title{
Morphological and Phylogenetic Characterization of Tyrophagus putrescentiae Schrank (Sarcoptiformes: Acaridae) from Hypsizygus marmoreus in Korea
}

\author{
Kwang Shik CHOI ${ }^{1}$, Jae Seok PARK ${ }^{2}$, Seung-Yeol LEE ${ }^{3}$, Do-Un HWANG ${ }^{1}$, \\ Hee-Young JUNG ${ }^{3 *}$ and Shoji OHGA*
}

\author{
Laboratory of Forest Resources Management, Division of Agro-environmental Sciences, \\ Department of Forest Environmental Sciences, Faculty of Agriculture, \\ Kyushu University, Sasaguri, Fukuoka 811-2415, Japan \\ (Received September 26, 2016 and accepted November 4, 2016)
}

\begin{abstract}
The present study reports the morphological and phylogenetic characteristics of Tyrophagus putrescentiae from Hypsizygus marmoreus in Korea. This species is morphologically characterized by two pigmented eyespots on the prodorsal shield, concave posterior margin of coxal plate II, prominently and apically enlarged supracoxal seta shaft at bases of pectinations, and solenidion omegal on tarsi I and II, respectively and length of setae $d 1$ compared to setae $c 1$ and setae $d 2$. The internal transcribed spacer 2 (ITS2) in the ribosomal DNA (rDNA), which is reliable for species identification, and the cytochrome oxidase subunit I (COI) in the mitochondrial DNA, which is a highly conserved region in eukaryotes, were sequenced. The resulting phylogenetic trees for COI and ITS2 apparently showed that the tested samples in this study were clustered with T. putrescentiae and separated from other species in the genus. This research would be useful for controlling mites from H. marmoreus in Korea and could help improve the quality and quantity of $H$. marmoreus production.
\end{abstract}

Key words: Tyrophagus putrescentiae, Hypsizygus marmoreus, COI, ITS2

\section{INTRODUCTION}

Mushrooms are one of the most cultivated crops in the world. Depending on the species and strain of mushroom, the environmental conditions and substrate resources required for cultivation differ (Dong and Wang, 2008; Qin and Qin, 2010). Some mite species prefer to live in wet environments and destroy stored foods such as cereals, grain, dog food, and flour, or organic matter debris (Rodriguez and Rodriguez, 1987). These mites can also survive in moist condition at $20-25^{\circ} \mathrm{C}$ for as long as 31 days without food (Sass et al., 2006). Since mushrooms are cultivated in warm and humid environments, control of pests, especially mites, is an economically important venture. Furthermore, domestic mites inhabit beds, carpets, and human living spaces (Spieksma, 1997). However, it is difficult to observe and control mites until the population density of the pests increases enough to cause noticeable damage (Wu and Lu, 1996; Lan et al., 2012).

The genus Tyrophagus is an economically important group of the superfamily Acaroidea. In particular, Tyrophagus putrescentiae, which is a non-predatory mite species is a common pest of stored foods and various fungi around the world (Chmielewski, 1978; Hubert et al., 2004, 2012; Nesvorná et al., 2012). This species has been reported from fungal and insect colonies in laboratories (Duek et al., 2001), indoor facilities, and the

\footnotetext{
College of Natural Science, Kyungpook National University, Daegu 41566, Korea

2 Evergreen Shimeji Farm, Cheongdo-gun 38321, Korea

3 College of Agriculture and Life Sciences, Kyungpook National University, Daegu 41566, Korea

* Corresponding author (e-mail: ohga@forest.kyushu-u.ac.jp, heeyoung@knu.ac.kr)
}

food industry (Solarz et al., 2007). It also lives in commercial bumblebee colonies (Rozej et al., 2012), agricultural soils (Smrz and Jungova, 1989) and the nests of small mammals and birds (O'Connor, 1979; O'Connor, 1982). In general, it feeds on protein and on fat-rich substances (Garcia, 2004; Palyvos et al., 2008; Erban et al., 2015; Erban et al., 2016). Infestation of this species on the mycelia and fruiting bodies of edible mushrooms decreases production and causes human allergic diseases (Li et al., 2003; Jeong et al., 2007). Previously T. putrescentiae has been found in Agaricus bisporus, Ganoderma lucidum, Lentinula edodes, Pleurotus ostreatus, and Pleurotus pulmonarius (Zou and Gao, 1987; Zhang et al., 1992).

Shimeji mushrooms, including $H$. marmoreus, is a mushroom group characterized by its bunched-together clusters with long stems and tight concave caps. Currently, production of shimeji mushrooms does not meet demand despite expansion of cultivation. Furthermore, farmers who cultivate $H$. marmoreus in Korea suffer economical losses from unidentified mites. Mite species have been identified generally using adult morphological characteristic keys, but their minuscule body sizes and the lack of morphological keys for egg and immature stages often make it difficult to identify these species (Vargas et al., 2005). Molecular diagnostic methods are useful for identifying acaroid mites at the species level, and the cytochrome oxidase subunit I (COI) in the mitochondrial DNA (mtDNA) and the internal transcribed spacer 2 (ITS2) in the ribosomal DNA (rDNA) have often been used for investigating relationships between and within species as well as for identifying mites to the species level (Ros and Breeuwer, 2007; Yang et al., 2011; Khaing et al., 2014). This study presents the results of studies on T. putrescentiae found on $H$. 
marmoreus in Korea using morphological characteristics and the phylogenetic trees of COI and ITS2.

\section{MATERIALS AND METHODS}

\section{Sample collection and morphological identification}

Specimens were collected for this study from pots used for H. marmoreus cultivation at a farm in Gaknammyeon, Cheongdo-gun, Gyeongsangbuk-do, Korea in 2016. After collection, mites were immediately selected for genomic DNA extraction and morphological identification. The specimens were morphologically identified under a stereo microscope (Carl Zeiss Axioskop 2, Germany) using the characteristic keys described by Fan and Zhang (2007).

\section{Molecular analysis}

A total of seven samples were used for the molecular study. For partial sequences of COI and ITS2, genomic DNA was extracted from mites using genomic DNA extraction kits (Bioneer Corp., Daejeon, Korea). Because the samples were so small, the genomic DNA extraction process was modified from the original manufacturer's protocol. The specimens were combined with $1 \times$ PBS and $5 \mu \mathrm{L}$ of Proteinase $\mathrm{K}$ in $1.5-\mathrm{mL}$ tubes. After grinding, $50 \mu \mathrm{L}$ of binding buffer was added and mixed immediately with a vortex mixer. The samples were incubated at $60^{\circ} \mathrm{C}$ for $10 \mathrm{~min}$. After adding $25 \mu \mathrm{L}$ of isopropanol, mites were washed with two types of washing buffers. Genomic DNA in the columns was eluted with an elution buffer. Polymerase chain reaction (PCR) was performed using forward (5'-GTTTTGGGATATCTCTCATAC-3') and reverse (5'-GAGCAACAACATAATAAGTATC-3') for COI and forward (5'-CGACTTTCGAACGCATATTGC-3') and reverse (5'-GCTTAAATTCAGGGGGTAA TCTCG-3') for ITS2 (Yang et al., 2011). A total volume of $25 \mu \mathrm{L}$ for each PCR reaction mixture contained $0.5 \mu \mathrm{L}$ of the genomic DNA, $1 \times$ PCR buffer, $1.5 \mathrm{mM} \mathrm{MgCl}_{2}, 0.2 \mathrm{mM}$ of each dNTP, $0.4 \mu \mathrm{M}$ of each primer for COI and ITS2, and 1 unit of Taq DNA polymerase. PCR cycling conditions for both regions proceeded as follows: initial denaturation step at $94^{\circ} \mathrm{C}$ for $5 \mathrm{~min}$ followed by 30 cycles at $94^{\circ} \mathrm{C} 40$ $\mathrm{sec}, 50^{\circ} \mathrm{C}(\mathrm{COI}) / 59^{\circ} \mathrm{C}$ (ITS2) for $40 \mathrm{sec}, 72^{\circ} \mathrm{C}$ for $1 \mathrm{~min}$, and a final extension at $72^{\circ} \mathrm{C}$ for $10 \mathrm{~min}$. PCR products were electrophoresed through an ethidium bromide $1.5 \%$ agarose gel, and a gel imaging system with ultraviolet light illumination was used to check the amplicons. After PCR purification using ExoSAP-IT (USB, Cleveland, OH, USA), PCR products were sent to SolGent Co., Ltd. (Daejeon, Korea) for DNA sequencing.

The sequence alignments for COI and ITS2 were carried out using BioEdit 7.2.5 (Hall, 1999). All sequences were deposited in GenBank under accession no. LC190827-LC190833 for ITS region and LC190834LC190839 for COI gene. Neighbor-joining (NJ) analysis was performed using MEGA 7.0 with 1000 bootstrap pseudo-replicates for node support (Kumar et al., 2016).

\section{RESULTS}

The morphological characteristics of the specimens for this study were examined using the key for $T$. putrescentiae (Fan and Zhang, 2007) (Fig. 1). In Figure 1, arrows and triangles indicate morphological fea-

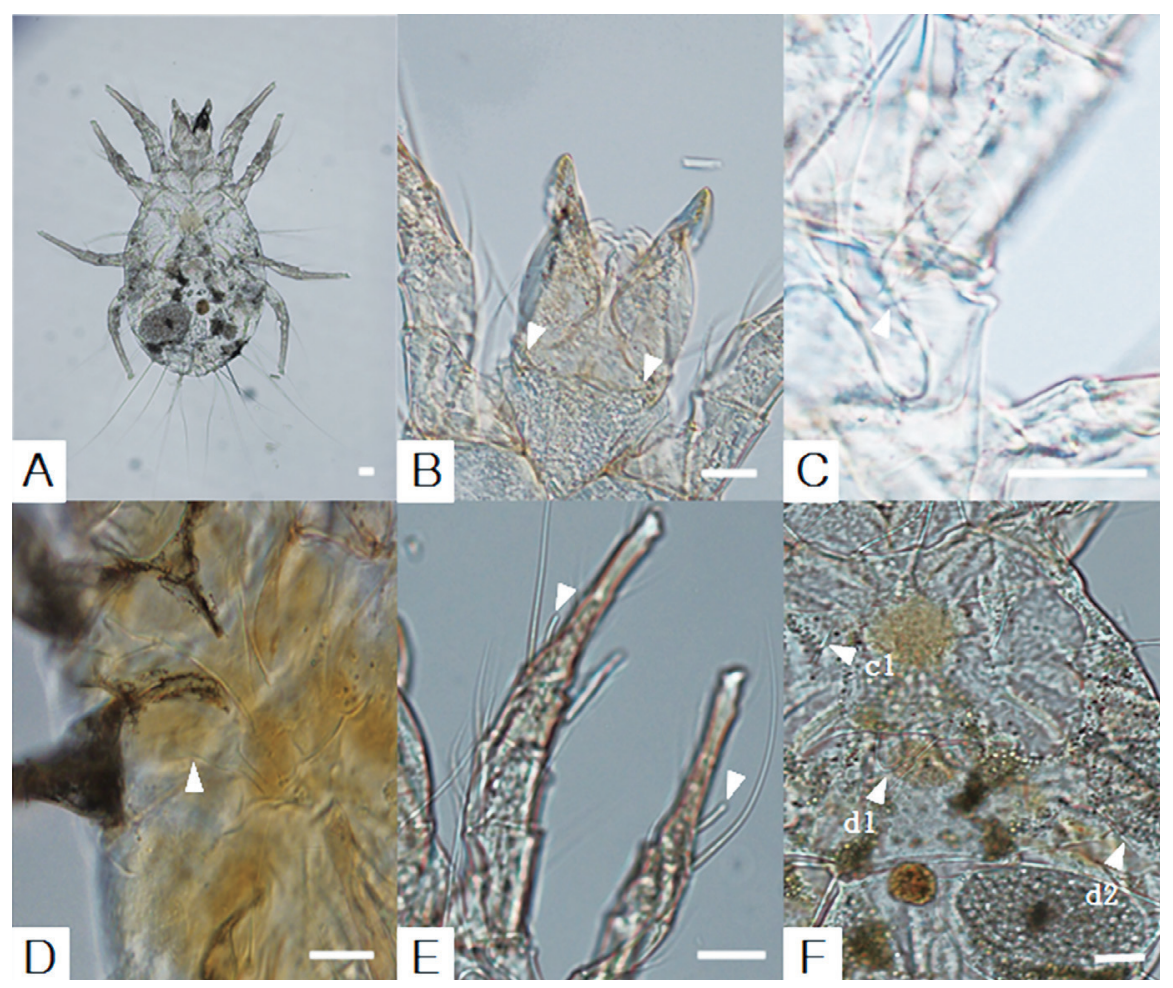

Fig. 1. Morphological characteristics of T. putrescentiae. A: Whole body of T. putrescentiae. B: Pigmented eyespots on prodorsal shield. C: Supracoxal setae at bases of pectinations. D: Posterior margin of coxal plate II. E: Solenidion omegal on tarsi I and II. F: Setae $c 1, d 1$, and $d 2$. Scale bars $=25 \mu \mathrm{m}$. 
tures of T. putrescentiae for identification such as pigmented eyespots, shaft of supracoxal setae, coxal plate II, solenidion omega1 on tarsi I and II, and setae $c 1, d 1$,

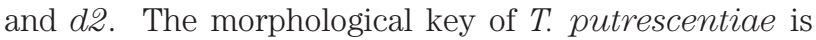
described as follows.

Key to T. putrescentiae (Fan and Zhang, 2007) Two pigmented eyespots on prodorsal shield; prominently enlarged shaft of supracoxal seta at bases of pectinations; concave posterior margin of coxal plate II; apically enlarged solenidion omega1 on tarsi I and II; setae d1 2.5 times or more than length of setae c1 and setae d2....... T. putrescentiae

The taxonomic comparison based on neighbor-joining analyses of COI and ITS2, which are identified in the present study and the GenBank database, are shown in Fig. 2 and Fig. 3. In an analysis of COI, all seven sample sequences were identical. The sequence alignments of COI in this study were branched into four clusters. The samples in this study clustered together with the known COI sequence of T. putrescentiae from China (GenBank accession no. EU078968) although the known COI sequence of $T$. putrescentiae from Korea (GenBank accession no. KJ820777) was separated from the cluster. Tyrophagus longior (GenBank accession no. KR869095) and Tyrophagus similis (GenBank accession no. KM199641), which are the only available sequences in the genus from GenBank, were apparently separated from the clusters of T. putrescentiae. Aleuroglyphus ovatus (GenBank accession no. EU078964) was used as an outer group of the COI analysis. The analysis of COI in this study clearly showed distinct clusters between species.

The phylogenetic tree of ITS2 showed two main clusters. All samples in this study clustered together with the known ITS2 sequences of T. putrescentiae from Korea, Japan, and China from GenBank (accession no. KJ605165, AB104977, and GQ205623 respectively) and were clearly distinguished from the other species clusters. Two clusters for Tyrophagus neiswanderi and
Tyrophagus fanetzhangorum (GenBank accession no. AB105036 and KC215303 respectively) were separated from the cluster of $T$. putrescentiae. Two clusters for $T$. similis and T. longior (GenBank accession no. AB104978 and AB104997 respectively) were apparently separated from the other species clusters. Tyroborus lini (GenBank accession no. AB105024) was used as an outer group of the ITS2 analysis. The analysis of ITS2 also prominently showed distinct clusters between species.

\section{DISCUSSION}

Tyrophagus putrescentiae found on H. marmoreus in Korea was morphologically and phylogenetically characterized in this study. There are at least 18 species in the genus Tyrophagus, which include Tyrophagus curvipenis Fain \& Fauvel, Tyrophagus debrivorus Chinniah \& Mohanasundaram, Tyrophagus glossinarum Fain, Tyrophagus houstoni Fain, Tyrophagus jingdezhenensis Jiang-Zhenta, Tyrophagus lini Oudemans, T. longior Gervais, Tyrophagus mimlongior Jiang, T. neiswanderi Johnson \& Bruce, Tyrophagus neotropicus Oudemans, Tyrophagus palmarum Oudemans, Tyrophagus perniciosus Zakhvatkin, T. putrescentiae Schrank, Tyrophagus robertsonae Lynch, Tyrophagus savasi Lynch, T. similis Volgin, Tyrophagus tropicus Robertson, T. fanetzhangorum Klimov \& O'Connor (O'Connor, 2008; Klimov and O'Connor, 2009). Tyrophagus putrescentiae was morphologically identified by means of a number of pigmented eyespots on the prodorsal shield, enlargements of supracoxal seta shaft at the bases of pectinations and solenidion omega1 on tarsi I and II, the posterior margin shape of coxal plates II, and length comparison between setae $c 1, d 1$, and $d 2$. However, species information is still needed for most of the species in this genus, including information on immature stages, in order to conduct a full investigation.

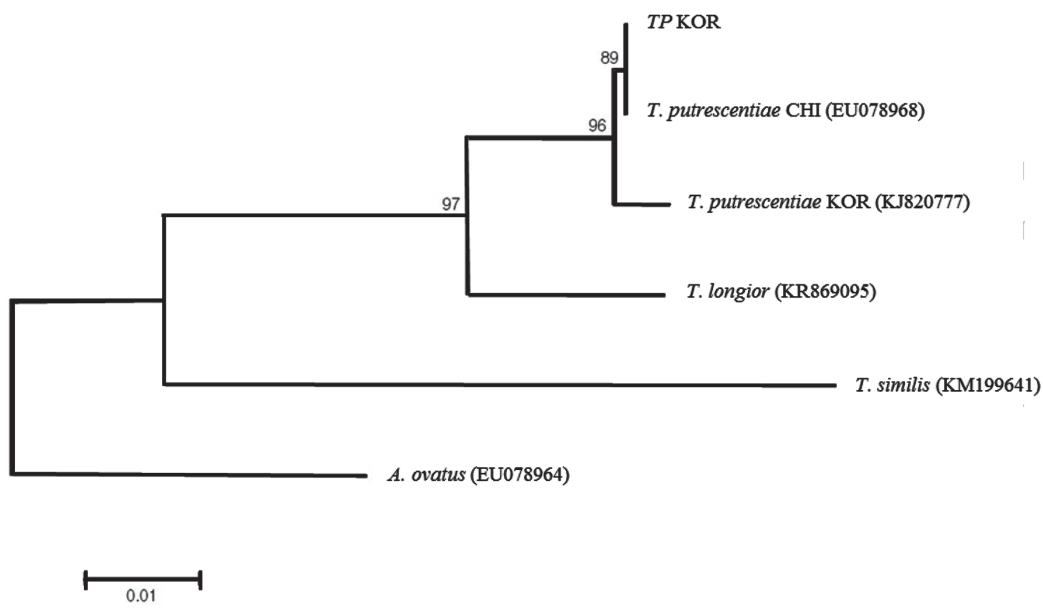

Fig. 2. Neighbor-joining tree for COI. Node support is given as bootstrap percentages for 1,000 replicates. One haplotype of T. putrescentiae for COI (TP KOR) in this study was produced. Tyrophagus putrescentiae KOR and CHI indicate strains of T. putrescentiae from Korea and China respectively. Aleuroglyphus ovatus was used as an outgroup for the analysis. 


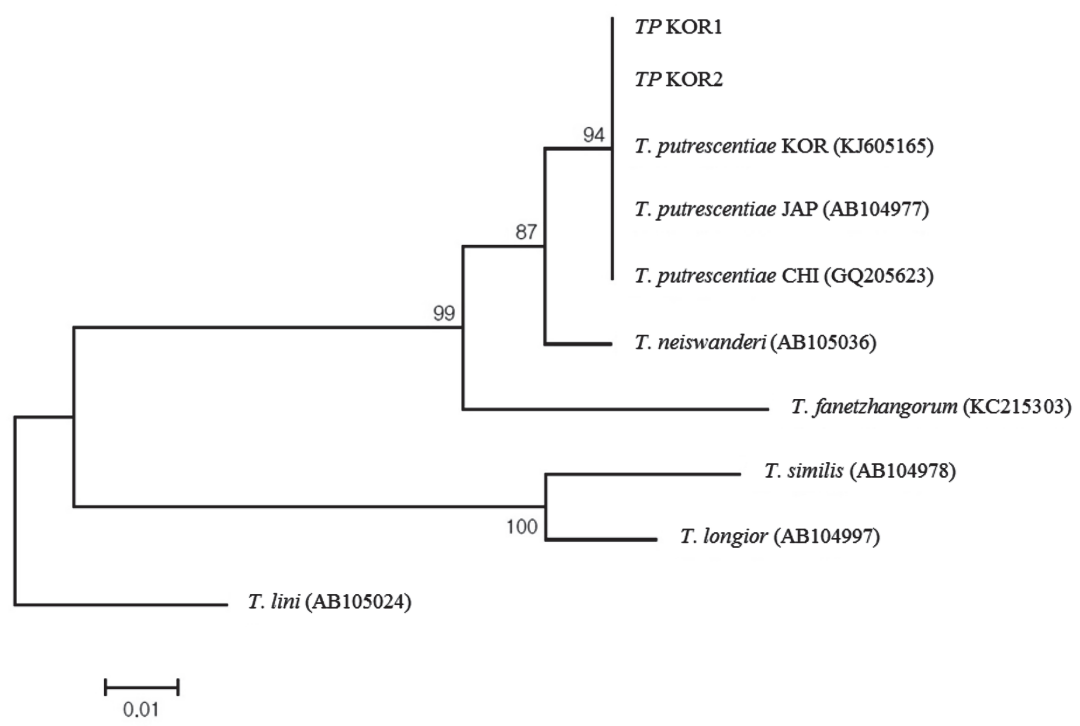

Fig. 3. Neighbor-joining tree for ITS2. Node support is given as bootstrap percentages for 1,000 replicates. Two haplotypes of T. putrescentiae for ITS2 (TP KOR1 and TP KOR2) were produced in this study. Tyrophagus putrescentiae KOR, JAP and CHI indicate strains of T. putrescentiae from Korea, Japan, and China respectively. Tyroborus lini is an outgroup for the analysis.

mtDNA is haploid and non-recombinant (Dowton and Campbell, 2001). Based on these features, phylogenetic studies often use regions of mtDNA as molecular markers, such as COI used for a DNA barcoding region and cytochrome oxidase subunit II (COII), NADH dehydrogenase subunit 5 (ND5) and cytochrome b (CYTb) genes for species identification. In this study, there were four clusters in the phylogenetic tree of COI. Two species, T. longior and T. similis, were apparently separated from T. putrescentiae. Tyrophagus putrescentiae was branched into two clusters. One cluster grouped the samples from this study and the COI sequence of $T$. putrescentiae from China, and the other cluster comprised the COI sequence of T. putrescentiae from Korea. Yang et al. (2011) showed two clusters within T. putrescentiae from China in the analysis of COI. Khaing et al. (2014) reported that two strains of T. putrescentiae from Korea and China, which were the same as those used in this study, were separated in their analysis of COI. This separation might be the result of the influence of food and habitats found in different environments. However, the clusters of T. putrescentiae for COI were distinctly separated from the other mite species.

The analysis of ITS2 in this study showed that all clusters for each species were clearly separated in the phylogenetic tree, including T. putrescentiae from Korea, Japan, and China. Although sequence variation in most of the coding regions in the rDNA is limited by selection, the low level of evolutionary constraint in some of the spacers and even functional domains, combined with the presence of tandem repeats in rDNA and their subsequent homogenization (Dover 1982), can lead to the rapid spread of a new sequence variant. Genetically isolated populations thus may be rapidly homogenized for different variants. Therefore, sequence variation between closely related species in the internal transcribed spacer
1 (ITS1) or ITS2 regions of the rDNA is reliable for species identification, including for mite species (Hillis and Dixon, 1991; Navajas and Fenton, 2000; de Rojas et al., 2007; Beroiz et al., 2014). Yang et al. (2011) and Khaing et al. (2014) reported that the analysis of ITS2 clearly distinguished mite species with two haplotypes for $T$. putrescentiae. Beroiz et al. (2014) also reported that five species in the genus Tyrophagus-T. putrescentiae, T. neiswanderi, T. fanetzhangorum, T. similis, and $T$. longior-were apparently separated, with several haplotypes for each species. Although there were several haplotypes of ITS2 within species, the five species in the genus Tyrophagus - at least those which were analyzed in this study and others-were distinctly separated in the analysis of ITS2.

In conclusion, T. putrescentiae was represented using the characterization of its morphological features and by molecular analyses of COI and ITS2. This study can provide useful information for the control of this mite species on $H$. marmoreus, and may prove helpful in improving the profits of mushroom farmers.

\section{ACKNOWLEDGEMENT}

This work was supported under the framework of international cooperation program managed by National Research Foundation of Korea (Grant Number: NRF2014K2A1A2048384).

\section{REFERENCES}

Beroiz, B., F. Couso-Ferrer, F. Ortego, M. J. Chamorro, C. Arteaga, M. Lombardero, P. Castanera and P. Hernandez-Crespo 2014 Mite species identification in the production of allergenic extracts for clinical use and in environmental samples by ribosomal DNA amplification. Med. Vet. Entomol., 28: 287-296 
Chmielewski, W. 1978 Mites, pests of the stored products and the allergies. Ochr. Rosl., 22: 16-17

Dong, X. J., and Q. Wang 2008 Classification and treatment of mushroom substrates. Beijing Agric., 8: 27-29

Dover, G. A. 1982 Molecular drive: a cohesive mode of species evolution. Nature, 299: 111-117

Dowton, M. and N. J. H. Campbell 2001 Intramitochondrial recombination - is it why some mitochondrial genes sleep around? Trends Ecol. Evol., 16: 269-271

Duek, L., G. Kaufman, E. Palevsky and I. Berdicevsky 2001 Mites in fungal cultures. Mycoses, 44: 390-394

Erban, T., D. Rybanska and J. Hubert 2015 Population growth of the generalist mite Tyrophagus putrescentiae (Acari: Acaridida) following adaptation to high- or low-fat and highor low-protein diets and the effect of dietary switch. Environ. Entomol., 44: 1599-1604

Erban, T., D. Rybanska, K. Harant, B. Hortova and J. Hubert 2016 Feces derived allergens of Tyrophagus putrescentiae reared on dried dog food and evidence of the strong nutritional interaction between the mite and Bacillus cereus producing protease bacillolysins and exo-chitinases. Front. Physiol., 7: 53

Fan, Q.-H. and Z.-Q. Zhang 2007 Revision of some species of Tyrophagus (Acari: Acaridae) in the Oudemans collection. Syst. Appl. Acarol., 12: 253-280

Garcia, N. 2004 Efforts to control mites on Iberian ham by physical methods. Exp. Appl. Acarol., 32: 41-50

Hall, T. A. 1999 Bioedit: a user-friendly biological sequence alignment editor and analysis program for Windows 95/98/NT. Nucleic Acids Symp. Series, 41: 95-98

Hillis, D. M. and M. T. Dixon 1991 Ribosomal DNA - molecular evolution and phylogenetic inference. Q. Rev. Biol., 66: 411453

Hubert, J., V. Jarosik, J. Mourek, A. Kubatova and E. Zdarkova 2004 Astigmatid mite growth and fungi preference (Acari: Acaridida): Comparisons in laboratory experiments. Pedobiologia 48: 205-214

Hubert, J., M. Nesvorná, M. Ságová-Marečková and J. Kopecký 2012 Shift of bacterial community in synanthropic mite Tyrophagus putrescentiae induced by Fusarium fungal diet. PLoS One, 7: e48429

Jeong, K., Y. H. Lee, J. S. Lee, J. Lee, I. Y. Lee, H. I. Ree and T. S. Yong 2007 Molecular cloning and the allergenic characterization of tropomyosin from Tyrophagus putrescentiae. Protein Pept. Lett., 14: 431-436

Khaing, T. M., J.-K. Shim and K.-Y. Lee 2014 Molecular identification and phylogenetic analysis of economically important acaroid mites (Acari: Astigmata: Acaroidea) in Korea. Entomol. Res., 44: 331-337

Klimov, P. B. and B. M. O'Connor 2009 Conservation of the name Tyrophagus putrescentiae, a medically and economically important mite species (Acari: Acaridae). Int. J. Acarol., 35: $95-114$

Kumar, S., G. Stecher and K. Tamura 2016 MEGA7: Molecular evolutionary genetics analysis version 7.0 for bigger datasets. Mol. Biol. Evol., doi: 10.1093/molbev/msw054.

Lan, Q. X., Z. H. Lu and Q. H. Fan 2012 Research progress of mite species on mushroom. Fujian J. Agric. Sci., 27: 104-108

Li, C. P., Y. B. Cui, J. Wang, Q. G. Yang and Y. Tian 2003 Acaroid mite, intestinal and urinary acariasis. World J. Gastroenterol., 9: $874-877$

Navajas, M. and B. Fenton 2000 The application of molecular markers in the study of diversity in acarology: a review. Exp. Appl. Acarol., 24: 751-774

Nesvorná, M., L. Gabrielova and J. Hubert 2012 Tyrophagus putrescentiae is able to graze and develop on Fusarium fungi of mycotoxins importance under laboratory conditions. $J$. Stored Prod. Res., 48: 37-45
O'Connor, B. M. 1979 "Evolutionary origins of astigmatid mites inhabiting stored products," in Proceedings of the $V$ International Congress of Acarology: Recent Advances in Acarology, Volume 1, August 6-12, 1978 Michigan State University, East Lansing ed. Rodriguez G. J., editor. (New York, NY: Academic Press) 273-278

O'Connor, B. M. 1982 Evolutionary ecology of astigmatid mites. Annu. Rev. Entomol., 27: 385-409

O'Connor, B. M., ed. 2008 "Acaridae Species Listing". Biology Catalog. Texas A\&M University. Retrieved July 26, 2010.

Palyvos, N. E., N. G. Emmanouel and C. J. Saitanis 2008 Mites associated with stored products in Greece. Exp. Appl. Acarol., 44: $213-226$

Qin, B. S. and Y. R. Qin 2010 Present research situation and prospect on new kinds of edible fungi's culture medium. Chin. Agric. Sci. Bull., 26: 223-228

Rodriguez, J. G. and L. D. Rodriguez 1987 Nutritional Ecology of Stored Product and House Dust Mites. In: F. Slansky, J.G. Rodruquez (Eds). Nutritional Ecology of Insects, Mites, Spiders, and Related Invertebrates. Wiley. pp. 345-368

Rojas, M., J. M. Ubeda, C. Cutillas, M. D. Mora, C. Ariza and D. Guevara 2007 Utility of ITS1, 5.8S, ITS2 and 16S mitochondrial DNA sequences for species identification and phylogenetic inference within the Rhinonyssus coniventris species complex (Acari: Rhinonyssidae). Parasitol. Res., 100: 10411046

Ros, V. I. D. and J. A. J. Breeuwer 2007 Spider mite (Acari: Tetranychidae) mitochondrial COI phylogeny reviewed: host plant relationships, phylogeography, reproductive parasites and barcoding. Exp Appl Acarol., 42: 239-262

Rozej E., W. Witalinski, H. Szentgyorgyi, M. Wantuch, D. Moron, M. Woyciechowski 2012 Mite species inhabiting commercial bumblebee (Bombus terrestris) nests in Polish greenhouses. Exp. Appl. Acarol., 56: 271-282

Sass, B. D., W. Wyatt Hoback 2006 Effects of Temperature and Humidity on Grain Mite, Acarus siro, Survival, ESA/NCB Meeting

Scott, J. A., W. G. Brogdon and F. H. Collins 1993 Identification of single specimens of the Anopheles gambiae complex by the polymerase chain reaction. Am. J. Trop. Med. Hyg., 49 520-529

Smrz, J. and V. Catska 1989 The effect of the consumption of some soil fungi on the internal microanatomy of the mite Tyrophagus putrescentiae (Schrank) (Acari. Acaridida) Acta Univ. Carol. Biol., 33: 81-93

Solarz, K., L. Senczuk, H. Maniurka, E. Cichecka and M. Peszke 2007 Comparisons of the allergenic mite prevalence in dwellings and certain outdoor environments of the Upper Silesia (southwest Poland). Int. J. Hyg. Environ. Health, 210: 715724

Spieksma, F. T. M. 1997 Domestic mites from an acarologic perspective. Allergy 52: 360-368

Vargas, M., M. Garcia-varela, J. P. Laclette and T. M. Perez 2005 Application of ITS-2 sequences as markers for identification and phylogenetic inference within the genus Geomylichus (Acari: Listrophoridae). Exp. Appl. Acarol., 35: 223-238

Wu, G. R. and Y. J. Lu 1996 Investigations on the fungi-phagous mites and their infection modes in mushroom cultures. Acta Phytophy. Sin., 23: 17-19

Yang, B., J. Cai and X. Cheng 2011 Identification of astigmatid mites using ITS2 and COI regions. Parasitol. Res., 108: 497503

Zhang, Y. X., J. Z. Lin, J. H. Huang and P. G. Zhu 1992 Studies on Tyrophagus putreseentiae (Schrank) and its damage to the edible fungi. J. Fujian Agric. Sci., 7: 91-94

Zou, P. and J. R. Gao 1987 The introduction of common species of mites in mushroom. Edible Fungi, 3: 29 